\title{
Frequency and Location of Supernumerary Teeth in a Private Hospital of Karachi City
}

\author{
Syed Ahmed Omer, Seema Nisar, Perveen Memon, Hamidullah Arif, Raza Ali, Samra Faheem
}

\begin{abstract}
:
Objective: To investigate frequency of supernumerary tooth in relation to gender, age and location.

Study Design and Setting: Cross-sectional Study was conducted at Mamji Hospital, Karachi from June 2017 to June 2019. Methodology: A total of 2160 patients seen and out of which 45 clinically diagnosed patients of supernumerary teeth were participated in this study. Supernumerary teeth were classified on the basis of location. Descriptive statistics were checked by means of percentages and frequency of all variables. Chi-Square test was applied, P-value $<0.05$ was considered
\end{abstract} significant.

Results: The total patients were 45 which comprised of 26 male and 19 females with ages ranging from 15 to 60 years. The prevalence of ST was $1.59 \%$, the higher predilection of supernumerary teeth was seen in males than females. The male to female's ratio was 1.36:1. On the basis of location ST were further classified on Mesiodens, Paramolars and Distomolars category. Of the 45 supernumerary teeth, 36 were had Mesiodens $(\mathrm{m}=62.1 \%, \mathrm{f}=37.8 \%), 5$ were Paramolars $(\mathrm{m}=60 \%$, $\mathrm{f}=40 \%)$ and 3 were Distomolars $(\mathrm{m}=0, \mathrm{f}=100 \%)$.

Conclusion: The present study findings showed high prevalence of ST was dominant in males. Present study emphasizes the timely diagnosis and appropriate management of supernumerary teeth to avoid unwanted complications.

Key Words: anomaly, prevalence, Supernumerary tooth, teeth,

\section{INTRODUCTION:}

Supernumerary teeth (ST) are developmental anomaly of number of teeth characterized by presence of extra tooth/teeth in the dental arch.1 It is also known as hyperdontia. ${ }^{2}$ ST may develop in any tooth bearing areas of the jaw in oral cavity. Clinically, ST may appear as a single tooth or multiple teeth in the oral cavity. It may also present unilaterally or bilaterally, erupted or impacted and in mandibular or maxillary arch. ${ }^{3}$ The prevalence of supernumerary teeth varies may range from $0.1 \%$ to $3.8 \%$ in the jaw, and it is most commonly reported in permanent dentition. The higher prevalence of ST were reported in Mongoloid groups than

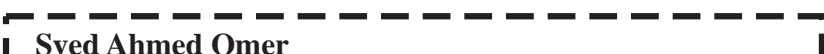

Assistant Professor \& HOD Department Science of Dental I Karachi

I Seema Nisar

Associate Professor, Department of Oral Biology

Liaquat University of Medical Health Sciences, Karachi

Perveen Memon

Associate Professor, Department of Oral Biology

I Liaquat University of Medical Health Sciences, Karachi

I Hamidullah Arif

I Senior Lecturer, Department of Community Health Sciences

I Bahria University Medical and Dental College, Karachi

I Raza Ali

I Senior Registrar, Department of Oral Medicine

Baqai Medical and Dental College, Karachi

Samra Faheem

Lecturer, Department of Oral Pathology

I Bahria University Medical and Dental College, Karachi

I Email: samrafaheem@hotmail.com

I Received: 27-Jan-2020

I Accepted: 16-Apr-2020

(1) in other racial groups. ${ }^{3,4}$ The incidence of ST has greatly seen in the maxilla, about $93.3 \%$ were located in anterior maxilla while $2.2 \%$ present in anterior region of mandible and posterior mandible accounted for $4.4 \%$ of supernumerary teeth. $^{2}$ The ST was more commonly seen in males as compared to females ${ }^{5,6}$ The ST are classified on the basis of location (Mesiodens, Paramolars, Distomolars) and morphology (conical, tuberculate, supplemental) The conical type of supernumerary teeth is most common. ${ }^{7,8}$

The etiology of ST exactly unknown, but several theories such as phylogenetic, dichotomy theory and occurrence of hyperactive dental lamina plays an important role in the etiology of Supernumerary teeth..$^{9}$ One theory suggests that the supernumerary tooth is created as a result of a dichotomy of the tooth bud. Another theory, well supported in the literature, is the hyperactivity theory, which suggests that supernumeraries are formed as a result of local, independent, conditioned hyperactivity of the dental lamina. Heredity may also play a role in the occurrence of this anomaly, the ST are more common in the relatives of affected children than in the general population. ${ }^{6}$

They are usually discovered incidentally by the dentist on routine radiographic examination and this may sometimes causes displacement of adjacent tooth, interference with orthodontic appliance and aesthetic issues for patients. ${ }^{10}$ The presence of a supernumerary tooth is the most common cause for the failure of eruption of a maxillary central incisor. It may also cause retention of the primary incisor teeth. The problem is usually reported with the eruption of the maxillary lateral incisors together with the failure of eruption of one or both central incisors. Supernumerary teeth in other 
locations may also cause failure of eruption of adjacent teeth. ${ }^{6}$ The supernumerary teeth can be transmitted as an autosomal dominant or autosomal recessive trait with incomplete penetrance, or may be associated with the $\mathrm{X}$ chromosome. Although there are some reports of multiple or bilaterally ST without any systemic conditions or associated syndromes, in most cases, ST are associated with other conditions or defects such as cleft lip/palate, cleidocranial dysostosis (CCD) and Gardner's syndrome, gardener syndrome, ${ }^{11}$ Ehlers-Danlos syndrome, Crouzon syndrome. ${ }^{12}$ craniosynostosis $^{13}$ and Enamel-Renal-Gingival syndrome. Less common syndromes that related with ST are; Fabry disease, Ellis-van Creveld (EvC) syndrome, Trico - Rhino - Phalangeal syndrome (TRPS), Nance-Horan syndrome, Rubinstein-Taybi syndrome. ${ }^{13,14}$

The supernumerary teeth are usually asymptomatic, and may diagnose during oral clinical examination. History and detailed examination and radiographic evaluation are mandatory. ${ }^{3}$ The present study data was gathered in a District Central Hospital to investigate the frequency of Supernumerary teeth according to site and morphology. This study also elucidates supernumerary teeth correlation with gender.

\section{METHODOLOGY:}

This cross-sectional study was carried out at Mamji hospital Karachi from June 2017 to June 2019, the ethical approval was obtained from Hospital ethical committee. A nonprobability convenient sampling technique was used. The sample size was calculated by using software OpenEpi.com by using prevalence of supernumerary teeth $3.8 \%$ and $95 \%$ Confidence interval. The required sample size was found to be 45 .

Out of 2160 patients seen in dental OPD over a period of 3 years. A total of 45 patients diagnosed with supernumerary tooth participated in the study. Informed consent was taken prior to examination of each patient. The study included both male and female patients of any age group. The ST was classified on the basis of location and morphology. The location was mesiodens, Paramolars and distomolars. Morphologically, ST was further divided into Conical, Tuberculate, Supplemental and Odontomes. The diagnosis of ST was made on clinical and radiological grounds. The patients suffering from any type of syndrome or craniofacial anomalies ${ }^{5}$ was also investigated. The exclusion criteria include patient refused to give consent, history of early age extractions and accidents.

The data was recorded on a proforma and analyzed by Statistical Package for the Social Sciences (SPSS) version 23. Frequency and percentages presented for categorical variables. To know the significance between gender and location of ST analysis was made using Chi-square test. Pvalue $<0.05$ was considered significant.

\section{RESULTS:}

Out of 2160 patient sample size collected over an estimated period of three years, 45 patients were clinically diagnosed with supernumerary teeth in this study. Out of which 26 were male $(57.8 \%)$ and 19 were females $(42.4 \%)$ having a 1.36:1 male to female ratio. The mean age, median and standard deviation was found to be $30.67,30.00, \pm 9.686$ respectively. The overall prevalence of supernumerary reported in the present study was $1.59 \%$. Table 1 shows the highest number of ST was present in 32 years of age 4 $(8.89 \%)$.

On the basis of morphological characteristics, the correlation of supernumerary teeth with gender was also investigated which revealed that all the ST were detected in maxilla. In maxilla, the most common ST present in males were mesiodens 23(62.1\%) followed by Paramolars 3(60\%) and Distomolars 0(\%). In females, highest number of ST were mesiodens 14(37.8\%) followed by Paramolars 2 (40\%) and Distomolar 3 (100\%). This showed insignificant findings with a p-value of 0.76 . Table 2

In the current study, we also tried to find an association of supernumerary teeth with syndrome or other craniofacial anomalies. However, no syndrome or other anomalies were detected in ST patients.

\section{DISCUSSION:}

Supernumerary teeth are the notable dental anomaly of shape of teeth mostly seen in maxillary quadrant, however, it may also present in mandibular region. These may reveal in routine oral and radiographic examinations teeth. ${ }^{14}$ Researches has shown that ST has been reported in both the primary and permanent dentition. Increased incidence of this anomaly has been reported permanent teeth. ${ }^{15}$ The prevalence of supernumerary teeth was found to be $1.59 \%$ in permanent dentition in present study, while in Japanese reported $0.04 \% .^{16}$ Study conducted by Shilpa in South Indian Children showed the overall prevalence rate of ST was $0.21 \%$ in primary dentition. ${ }^{17}$

The etiology of supernumerary teeth remains unclear. However, various theories have been suggested regarding the presence of supernumerary teeth. The widely accepted theory for splitting of the dental follicle (Dichotomy theory), some factors such as trauma or evolutionary mutations, can cause accidental follicle division into two or more fragments. ${ }^{18}$ The hyperactivity of the dental lamina and the combination of genetic and environmental factors may be considered as the most acceptable etiologic factors in the development of mesiodens. ${ }^{19,20,21 .}$ Familial occurrence of mesiodens (ST developing between two central incisors) is reported to involve more than one sibling, or one generation. ${ }^{22,23}$

Supernumerary teeth have been classified primarily on the basis of location and morphology as shown in Table 3. Studies have shown that ST has been reported in patients 


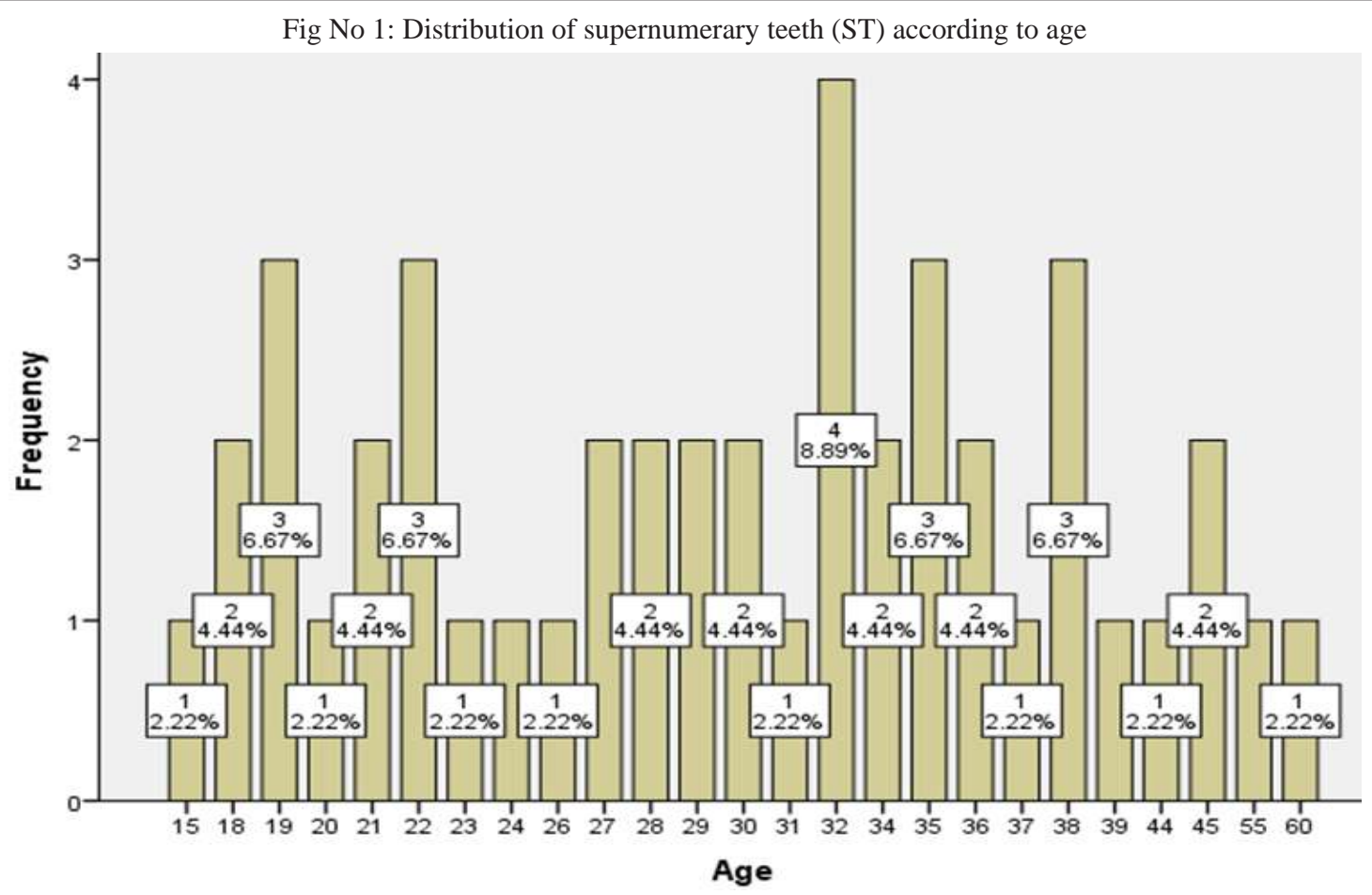

Table No 2: Distribution of Supernumerary teeth according to gender and location

\begin{tabular}{|c|c|c|c|}
\hline $\begin{array}{c}\text { Supernumerary Teeth } \\
\text { Present Based on Location }\end{array}$ & \multicolumn{2}{|c|}{ Gender $(\mathbf{n = 4 5})$} & \multirow{2}{*}{ P-Value } \\
\hline & Male & Female & \\
\hline Mesiodens & $23(62.1 \%)$ & $14(37.8 \%)$ & \multirow{2}{*}{.076} \\
\hline Paramolars & $3(60 \%)$ & $2(40 \%)$ & \multirow{2}{*}{} \\
\hline Distomolars & $0(0 \%)$ & $3(100 \%)$ & \\
\hline Total & 26 & 19 & \\
\hline
\end{tabular}

*Chi-square test was applied to see the significance level. $*$ P-value $<0.05$ considered to be statistically significant.

Table No 3: Classification of Supernumerary Teeth

\begin{tabular}{|c|c|}
\hline Based on location & Based on Morphology \\
\hline Mesiodens & Conical \\
\hline Paramolars & Tuberculate \\
\hline Distomolar & Supplemental \\
\hline & Odontome \\
\hline
\end{tabular}

having syndromes and other craniofacial anomalies such as cleft lip and palate, Gardner's syndrome, Down syndrome and cleidocranial dysostosis. ${ }^{24}$ The ST has shown a strong association with Ehlers-Danlos syndrome, Fabry Anderson's syndrome, chondroectodermal dysplasia, incontinentia pigmenti and tricho rhino-phalangeal syndrome. ${ }^{17,18,}$ Evidences also revealed that $\mathrm{ST}$ is also seen in non syndromic patients $^{7,12}$. In present study we also investigated the association of ST with syndromes. The current study findings did not observe any case of ST in syndromic patient. However, all were detected in non-syndromic patients. Clinically, ST can appear in any region of the jaws. The most commonly involve site is the premaxilla. ${ }^{21,22,23}$ Based on location the mesiodens is the supernumerary tooth present between two maxillary central incisors. In present study, the mesiodens was higher in proportion followed by Paramolars and distomolars. Higher predilection was seen in males as compared to females. Leco and colleagues discovered that the mesiodens was the most frequent supernumerary teeth found in the maxilla. ${ }^{24}$ The Ferres-Padro conducted study on patient age ranging from between 5 to 19 years of age showed mesiodens were the most frequently found supernumerary teeth $(53.16 \%)$. Similar results were also observed in Sharma and Singh study and found that $81.2 \%$ of the ST were located in the central incisor region (mesiodens $30.0 \%)^{21,25}$.

The supernumerary teeth are usually asymptomatic and it may detect as an incidental finding during clinical and radiographic examination. For the proper diagnosis of ST the detailed history, clinical examination, radiographic investigation is mandatory for definitive diagnosis ${ }^{26,27,28}$. Evidences have shown that unerupted supernumerary tooth may be found by chance during radiographic examination. It is recommended that anterior occlusal or periapical radiograph, paralleling technique and orthopantomogram are the most useful investigations to visualize supernumerary teeth. Recently, computed tomography has also been used to detect the presence of supernumerary teeth. ${ }^{29,30}$

\section{CONCLUSION:}

The present study findings showed high prevalence of ST was dominant in males. Present study emphasizes the timely 
diagnosis and appropriate management of supernumerary teeth to avoid unwanted complications.

\section{REFRENCES:}

1. Alberti G, Mondani PM, Parodi V. Eruption of supernumerary permanent teeth in a sample of urban primary school population in Genoa, Italy. Eur J Paediatr Dent 2006;7:89-92.

2. Syriac G, Joseph E, Rupesh S, Philip J, Cherian SA, Mathew J. Prevalence, Characteristics, and Complications of Supernumerary Teeth in Nonsyndromic Pediatric Population of South India: A Clinical and Radiographic Study. J Pharm Bioallied Sci. 2017;9(Suppl 1):S231-S236.

3. Parolia A, Kundabala M, Dahal M, Mohan M, Thomas MS. Management of supernumerary teeth. J Conserv Dent. 2011;14(3):221-224.

4. Yusof WZ. Non-syndromal multiple supernumerary teeth: Literature review. J Can Dent Assoc. 1990;56:147-9.

5. Kinirons MJ. Unerupted premaxillary supernumerary teeth. A study of their occurrence in males and females. Br Dent J. 1982;153:110.

6. Garvey MT, Barry HJ, Blake M. Supernumerary teeth- an overview of classification, diagnosis and management. J Can Dent Assoc. 1999;65:612-6.

7. Shah A, Gill DS, Tredwin C, Naini FB. Diagnosis and management of supernumerary teeth. Dental Update. 2008;35:510-20.

8. Leco Berrocal M, Martin Morales JF, Martinez González JM. An observational study of the frequency of supernumerary teeth in a population of 2000 patients. Med Oral Patol Oral Cir Bucal 2007;12:E134-8

9. Fleming PS, Xavier GM, DiBiase AT, Cobourne MT. Revisiting the supernumerary: the epidemiological and molecular basis of extra teeth. Br Dent J 2010; 208:25-30;

10. Ferreira O, Cardoso CL, Capelozza ALA, Yaedú RYF, da Costa AR. Odontogenic keratocyst and multiple supernumerary teeth in a patient with Ehlers-Danlos syndrome-a case report and review of the literature. Quintessence Int 2008; 39:2516; PMID:18618041

11. Torun GS, Akbulut A. Crouzon syndrome with multiple supernumerary teeth. Niger J Clin Pract 2017; 20:261-3; PMID:28091449; https://doi.org/10.4103/1119-3077.187332

12. Nieminen P, Morgan NV, Fenwick AL, Parmanen S, Veistinen L, Mikkola ML, van der Spek PJ, Giraud A, Judd L, Arte S, et al.. Inactivation of IL11 signaling causes craniosynostosis, delayed tooth eruption, and supernumerary teeth. Am J Hum Genet 2011; 89:67-81

13. Kantaputra PN, Kaewgahya M, Khemaleelakul U, Dejkhamron $\mathrm{P}$, Sutthimethakorn S, Thongboonkerd V, Iamaroon A. Enamelrenal-gingival syndrome and FAM20A mutations. Am J Med Genet 2014; 164A:1-9; PMID:24259279; https://doi.org/ 10.1002 /ajmg.a.36187
14. Mukhopadhyay S. Mesiodens: A clinical and radiographic study in children. J Indian Soc Pedod Prev Dent. 2011;29:34-8

15. Demiriz L, Durmuplar MC, Mýsýr AF. Prevalence and characteristics of supernumerary teeth: A survey on 7348 people. J Int Soc Prev Community Dent. 2015;5(Suppl 1):S39-S43. doi:10.4103/2231-0762.156151

16. Hagiwara Y, Uehara T, Narita T, Tsutsumi H, Nakabayashi $\mathrm{S}$, Araki M Odontology Prevalence and distribution of anomalies of permanent dentition in 9584 Japanese high school students.. 2016 Sep; 104(3):380-9

17. Shilpa G, Gokhale N, Mallineni SK, Nuvvula S J Indian Soc Pedod Prev Dent. Prevalence of dental anomalies in deciduous dentition and its association with succedaneous dentition: A cross-sectional study of 4180 South Indian children. 2017 Jan-Mar; 35(1):56-62.

18. . Supernumerary Teeth: Review of the Literature with Recent Updates. Volume 2014, Article ID 764050, 6 pages

19. Stellzig A, Basdra EK, Komposch G. Mesiodentes: Incidence, morphology, etiology. J Orofac Orthop 1997; 58: 144-53.

20. Gallas MM, Garcia A. Retention of permanent incisors by mesiodens: A family affair. Br Dent J 2000; 188: 63-4.

21. Liu JF. Characteristics of premaxillary supernumerary teeth: A survey of 112 cases. ASDC J Dent Child 1995; 62: 262-5.

22. Van Buggenhout G, Bailleul-Forestier I. Mesiodens. Eur J Med Genet 2008; 51: 178-81.

23. Gorlin RJ, CM, Hennekam RC. Syndromes of the head and neck. 4th ed. Oxford University Press; 2001.

24. Leco Berrocal M, Martin Morales JF, Martinez González JM. An observational study of the frequency of supernumerary teeth in a population of 2000 patients. Med Oral Patol Oral Cir Bucal 2007;12:E134-8

25. Ferrés-Padró E, Prats-Armengol J, Ferrés-Amat E. A descriptive study of 113 unerupted supernumerary teeth in 79 pediatric patients in Barcelona. Med Oral Patol Oral Cir Bucal 2009;14:E146-52

26. Grimanis GA, Kyriakides AT, Spyropoulos ND. A survey on supernumerary molars. Quintessence Int. 1991;22:989-9

27. Rajab LD, Hamdan MA. Supernumerary teeth: Review of the literature and a survey of 152 cases. Int J Pediatr Dent. 2002;12:244-54.

28. Brook AH. Dental anomalies of number, form and size: Their prevalence in British school children. J Int Assoc Dent Child. 1974;5:37-53.

29. Scheiner MA, Sampson WJ. Supernumerary teeth: A review of the literature and four case reports. Aus Dent J. 1997;42:160-5.

30. De Oliveira Gomes C, Drummond SN, Jham BC, Abdo EN, Mesquita RA. A survey of 460 supernumerary teeth in Brazilian children and adolescents. Int J Paediatr Dent. 2008;18:98-106. 